DOI: $10.17516 / 1997-1397-2020-13-4-492-502$

УДК 514.7

\title{
Generalized Contractions to Coupled Fixed Point Theorems in Partially Ordered Metric Spaces
}

\author{
N. Seshagiri Rao* \\ Department of Applied Mathematics \\ School of Applied Natural Sciences \\ Adama Science and Technology University \\ Adama, Ethiopia \\ Karusala Kalyani ${ }^{\dagger}$ \\ Department of Mathematics \\ Vignan's Foundation for Science, Technology \& Research \\ Andhra Pradesh, India
}

Received 06.04.2020, received in revised form 25.04.2020, accepted 16.05.2020

\begin{abstract}
The purpose of this paper is to establish some coupled fixed point theorems for a self mapping satisfying certain rational type contractions along with strict mixed monotone property in a metric space endowed with partial order. Also, we have given the result of existence and uniqueness of a coupled fixed point for the mapping. This result generalize and extend several well known results in the literature.
\end{abstract}

Keywords: partially ordered metric spaces, rational contractions, coupled fixed point, monotone property.

Citation: N. Seshagiri Rao, K. Kalyani, Generalized Contractions to Coupled Fixed Point Theorems in Partially Ordered Metric Spaces, J. Sib. Fed. Univ. Math. Phys., 2020, 13(4), 492-502.

DOI: 10.17516/1997-1397-2020-13-4-492-502.

The existence and uniqueness of a fixed point was given by Banach [1] in 1922, which was acclaimed as Banach contraction principle and plays an important role in the development of various results connected with Fixed point Theory and Approximation Theory. The Banach's fixed point theorem or the contraction principle concerns certain mappings of a complete metric space into itself. It lays down conditions; sufficient for the existence and uniqueness of a fixed point. Besides, this famous classical theorem gives an iteration process through which we can obtain better approximation to the fixed point. Banach's fixed point theorem has rendered a key role in solving systems of linear algebraic equations involving iteration process. Iteration procedures are used in nearly every branch of applied mathematics, convergence proof and also in estimating the process of errors, very often by an application of Banach's fixed point theorem.

After that several mathematicians contributed to the growth of this area of knowledge and extensively reported in their work by taking various conditions on mappings as well as on spaces (see [2-11]). Also, numerous generalizations of this theorem have been obtained by weakening its hypotheses on various spaces like rectangular metric spaces, pseudo metric spaces, fuzzy metric spaces, quasi metric spaces, quasi semi-metric spaces, probabilistic metric spaces, $D$ metric spaces, $G$-metric spaces, $F$-metric spaces, cone metric spaces, and so on. More work on fixed points, common fixed points results in cone metric spaces, partially ordered metric spaces and others spaces can see from [12-24]. Recently, The existence and uniqueness of coupled fixed points on ordered sets have been investigated by many authors with various conditions on the mappings, readers may refer to [25-42] and references therein.

*seshu.namana@gmail.com

$\dagger$ kalyani.namana@gmail.com

(c) Siberian Federal University. All rights reserved 
In this paper, we proved some coupled fixed point results in the frame work of partially ordered metric space satisfying a generalized contractive condition of rational type with strict mixed monotone property of the mapping. Also, we presented the existence and uniqueness of a coupled fixed point result for the mapping. These results generalized many well known results in partially ordered metric space.

\section{Preliminaries}

Definition 1. Let $(X, \leqslant)$ be a partially ordered set. A self mapping $f: X \rightarrow X$ is said to be strictly increasing if $f(x)<f(y)$, for all $x, y \in X$ with $x<y$ and is also said to be strictly decreasing if $f(x)>f(y)$, for all $x, y \in X$ with $x<y$.

Definition 2. Let $(X, \leqslant)$ be a partially ordered set and $f$ is a self mapping defined over $X$ is said to be strict mixed monotone property, if $f(x, y)$ is strictly increasing in $x$ and strictly decreasing in y as well.

$$
\begin{gathered}
\text { i.e., for any } x_{1}, x_{2} \in X \text { with } x_{1}<x_{2} \Rightarrow f\left(x_{1}, y\right)<f\left(x_{2}, y\right) \text { and also } \\
\text { for any } y_{1}, y_{2} \in X \text { with } y_{1}<y_{2} \Rightarrow f\left(x, y_{1}\right)>f\left(x, y_{2}\right) \text {. }
\end{gathered}
$$

Definition 3. Let $(X, \leqslant)$ be a partially ordered set and $f: X \times X \rightarrow X$ be a mapping. A point $(x, y) \in X \times X$ is said to be a coupled fixed point to $f$, if $f(x, y)=x$ and $f(y, x)=y$.

Definition 4 . The triple $(X, d, \leqslant)$ is called partially ordered metric space if $(X, \leqslant)$ is a partially ordered set together with $(X, d)$ is a metric space.

Definition 5. If $(X, d)$ is a complete metric space, then triple $(X, d, \leqslant)$ is called a partially ordered complete metric space.

Definition 6. A partially ordered metric space $(X, d, \leqslant)$ is called an ordered complete $(O C)$, if for each convergent sequence $\left\{x_{n}\right\}_{n=0}^{\infty} \subset X$, the following one of the condition holds

- if $\left\{x_{n}\right\}$ is a non-decreasing sequence in $X$ such that $x_{n} \rightarrow x$ then $x_{n} \leqslant x$, for all $n \in \mathbb{N}$ that is, $x=\sup \left\{x_{n}\right\}$ or

- if $\left\{x_{n}\right\}$ is a non-increasing sequence in $X$ such that $x_{n} \rightarrow x$ then $x \leqslant x_{n}$, for all $n \in \mathbb{N}$ that is, $x=\inf \left\{x_{n}\right\}$.

\section{Main results}

In this section, we prove some coupled fixed point theorems for a self mapping satisfying certain rational contraction condition in ordered metric space.

Theorem 1. Let $(X, d, \leqslant)$ be a complete partially ordered metric space. Suppose that a self mapping $f: X \times X \rightarrow X$ has a strict mixed monotone property on $X$ satisfying the following condition

$$
\begin{aligned}
d(f(x, y), f(\mu, v)) \leqslant & \alpha \frac{d(x, f(x, y))[1+d(\mu, f(\mu, v))]}{1+d(x, \mu)}+\beta \frac{d(x, f(x, y)) d(\mu, f(\mu, v))}{d(x, \mu)} \\
& +\gamma[d(x, f(x, y))+d(\mu, f(\mu, v))]+\delta[d(x, f(\mu, v))+d(\mu, f(x, y))] \\
& +\lambda d(x, \mu)
\end{aligned}
$$

for all $x, y, \mu, v \in X$ with $x \geqslant \mu$ and $y \leqslant v$, where $\alpha, \beta, \gamma, \delta, \lambda \in[0,1)$ with $0 \leqslant \alpha+\beta+2(\gamma+\delta)+$ $+\lambda<1$. Suppose that either $f$ is continuous or $X$ has an ordered complete property $(O C)$ then $f$ has a coupled fixed point $(x, y) \in X \times X$, if there exists two points $x_{0}, y_{0} \in X$ with $x_{0}<f\left(x_{0}, y_{0}\right)$ and $y_{0}>f\left(y_{0}, x_{0}\right)$. 
Proof. Suppose $f$ is a continuous map on $X$. Let $x_{0}, y_{0} \in X$ such that $x_{0}<f\left(x_{0}, y_{0}\right)$ and $y_{0}>f\left(y_{0}, x_{0}\right)$ then, define two sequences $\left\{x_{n}\right\},\left\{y_{n}\right\}$ in $X$ as follows

$$
x_{n+1}=f\left(x_{n}, y_{n}\right) \text { and } y_{n+1}=f\left(y_{n}, x_{n}\right) \text { for all } n \geqslant 0 \text {. }
$$

Next, we have to show that for all $n \geqslant 0$,

$$
x_{n}<x_{n+1}
$$

and

$$
y_{n}>y_{n+1}
$$

for this, we use the method of mathematical induction. Suppose $n=0$, since $x_{0}<f\left(x_{0}, y_{0}\right)$ and $y_{0}>f\left(y_{0}, x_{0}\right)$ and from (2), we have $x_{0}<f\left(x_{0}, y_{0}\right)=x_{1}$ and $y_{0}>f\left(y_{0}, x_{0}\right)=y_{1}$ and hence the inequalities (3) and (4) hold for $n=0$. Suppose that the inequalities (3) and (4) hold for all $n>0$ and by using the strict mixed monotone property of $f$, we get

$$
x_{n+1}=f\left(x_{n}, y_{n}\right)<f\left(x_{n+1}, y_{n}\right)<f\left(x_{n+1}, y_{n+1}\right)=x_{n+2}
$$

and

$$
y_{n+1}=f\left(y_{n}, x_{n}\right)>f\left(y_{n+1}, x_{n}\right)>f\left(y_{n+1}, x_{n+1}\right)=y_{n+2} .
$$

Thus, the inequalities (3) and (4) hold for all $n \geqslant 0$ and we obtain that

$$
x_{0}<x_{1}<x_{2}<x_{3}<\cdots<x_{n}<x_{n+1}<\cdots
$$

and

$$
y_{0}>y_{1}>y_{2}>y_{3}>\cdots>y_{n}>y_{n+1}>\cdots .
$$

We know that $x_{n}<x_{n+1}, y_{n}>y_{n+1}$ for all $n$ then, by (1) and use of (2), we get

$$
\begin{aligned}
d\left(x_{n+1}, x_{n}\right)= & d\left(f\left(x_{n}, y_{n}\right), f\left(x_{n-1}, y_{n-1}\right)\right) \\
\leqslant & \alpha \frac{d\left(x_{n}, f\left(x_{n}, y_{n}\right)\right)\left[1+d\left(x_{n-1}, f\left(x_{n-1}, y_{n-1}\right)\right)\right]}{1+d\left(x_{n}, x_{n-1}\right)} \\
& +\beta \frac{d\left(x_{n}, f\left(x_{n}, y_{n}\right)\right) d\left(x_{n-1}, f\left(x_{n-1}, y_{n-1}\right)\right)}{d\left(x_{n}, x_{n-1}\right)} \\
& +\gamma\left[d\left(x_{n}, f\left(x_{n}, y_{n}\right)\right)+d\left(x_{n-1}, f\left(x_{n-1}, y_{n-1}\right)\right)\right] \\
& +\delta\left[d\left(x_{n}, f\left(x_{n-1}, y_{n-1}\right)\right)+d\left(x_{n-1}, f\left(x_{n}, y_{n}\right)\right)\right]+\lambda d\left(x_{n}, x_{n-1}\right)
\end{aligned}
$$

which implies that

$$
\begin{aligned}
d\left(x_{n+1}, x_{n}\right) \leqslant & \alpha \frac{d\left(x_{n}, x_{n+1}\right)\left[1+d\left(x_{n-1}, x_{n}\right)\right]}{1+d\left(x_{n}, x_{n-1}\right)}+\beta \frac{d\left(x_{n}, x_{n+1}\right) d\left(x_{n-1}, x_{n}\right)}{d\left(x_{n}, x_{n-1}\right)} \\
& +\gamma\left[d\left(x_{n}, x_{n+1}\right)+d\left(x_{n-1}, x_{n}\right)\right]+\delta\left[d\left(x_{n}, x_{n}\right)+d\left(x_{n-1}, x_{n+1}\right)\right] \\
& +\lambda d\left(x_{n}, x_{n-1}\right) .
\end{aligned}
$$

Finally, we arrive at

$$
d\left(x_{n+1}, x_{n}\right) \leqslant\left(\frac{\gamma+\delta+\lambda}{1-\alpha-\beta-\gamma-\delta}\right) d\left(x_{n}, x_{n-1}\right) .
$$

Similarly by following above, we get

$$
d\left(y_{n+1}, y_{n}\right) \leqslant\left(\frac{\gamma+\delta+\lambda}{1-\alpha-\beta-\gamma-\delta}\right) d\left(y_{n}, y_{n-1}\right) .
$$


So, from equations (9) and (10), we have

$$
d\left(x_{n+1}, x_{n}\right)+d\left(y_{n+1}, y_{n}\right) \leqslant\left(\frac{\gamma+\delta+\lambda}{1-\alpha-\beta-\gamma-\delta}\right)\left[d\left(x_{n}, x_{n-1}\right)+d\left(y_{n}, y_{n-1}\right)\right] .
$$

Now, let us define a sequence $\left\{S_{n}\right\}$ in $X$ as $\left\{S_{n}\right\}=\left\{d\left(x_{n+1}, x_{n}\right)+d\left(y_{n+1}, y_{n}\right)\right\}$. Therefore, by induction we get

$$
0 \leqslant S_{n} \leqslant k S_{n-1} \leqslant k^{2} S_{n-2} \leqslant k^{3} S_{n-3} \leqslant \ldots \leqslant k^{n} S_{0},
$$

where $k=\frac{\gamma+\delta+\lambda}{1-\alpha-\beta-\gamma-\delta}<1$ and hence, we obtain

$$
\lim _{n \rightarrow+\infty} S_{n}=\lim _{n \rightarrow+\infty}\left[d\left(x_{n}, x_{n+1}\right)+d\left(y_{n}, y_{n+1}\right)\right]=0 .
$$

Consequently, we get $\lim _{n \rightarrow+\infty} d\left(x_{n}, x_{n+1}\right)=0$ and $\lim _{n \rightarrow+\infty} d\left(y_{n}, y_{n+1}\right)=0$. By using triangular inequality for $m \geqslant n$, we get

$$
d\left(x_{m}, x_{n}\right) \leqslant d\left(x_{m}, x_{m-1}\right)+d\left(x_{m-1}, x_{m-2}\right)+\cdots+d\left(x_{n+1}, x_{n}\right)
$$

and

$$
d\left(y_{m}, y_{n}\right) \leqslant d\left(y_{m}, y_{m-1}\right)+d\left(y_{m-1}, y_{m-2}\right)+\cdots+d\left(y_{n+1}, y_{n}\right) .
$$

Therefore,

$$
\begin{aligned}
d\left(x_{m}, x_{n}\right)+d\left(y_{m}, y_{n}\right) & \leqslant S_{m-1}+S_{m-2}+\cdots+S_{n} \\
& \leqslant\left(k^{m-1}+k^{m-2}+\cdots+k^{n}\right) S_{0} \\
& \leqslant \frac{k^{n}}{1-k} S_{0} .
\end{aligned}
$$

Letting limit as $n, m \rightarrow \infty$ in the above inequality, we obtain that $d\left(x_{m}, x_{n}\right)+d\left(y_{m}, y_{n}\right) \rightarrow 0$. Consequently, the sequences $\left\{x_{n}\right\}$ and $\left\{y_{n}\right\}$ are Cauchy sequences in $X$ and by completeness of $X$, there exists a point $(x, y) \in X \times X$ such that $x_{n} \rightarrow x$ and $y_{n} \rightarrow y$. And also from the continuity of $f$, we have

$$
x=\lim _{n \rightarrow \infty} x_{n+1}=\lim _{n \rightarrow \infty} f\left(x_{n}, y_{n}\right)=f\left(\lim _{n \rightarrow \infty} x_{n}, \lim _{n \rightarrow \infty} y_{n}\right)=f(x, y),
$$

and

$$
y=\lim _{n \rightarrow \infty} y_{n+1}=\lim _{n \rightarrow \infty} f\left(y_{n}, x_{n}\right)=f\left(\lim _{n \rightarrow \infty} y_{n}, \lim _{n \rightarrow \infty} x_{n}\right)=f(y, x) .
$$

Therefore, we have $x=f(x, y)$ and $y=f(y, x)$, i.e., $f$ has a coupled fixed point in $X \times X$.

Another way, suppose $X$ has an ordered complete property (OC). From above discussion there is an increasing Cauchy sequence $\left\{x_{n}\right\}$ in $X$ converges to $x \in X$. Then from (OC) property of $X$, we have $x=\sup \left\{x_{n}\right\}$, i.e., $x_{n} \leqslant x$, for all $n \in \mathbb{N}$. Therefore, we conclude that $x_{n}<x$, for all $n$ otherwise there exists a number $n_{0} \in \mathbb{N}$ such that $x_{n_{0}}=x$, and hence $x<x_{n_{0}} \leqslant x_{n_{0}+1}=x$ which is wrong. Thus, from the strict monotone increasing of $f$ over the first variable, we get

$$
f\left(x_{n}, y_{n}\right)<f\left(x, y_{n}\right) .
$$

Similarly, from above there is a decreasing Cauchy sequence $\left\{y_{n}\right\}$ in $X$, which converges to a point $y \in X$. Thus, by (OC) property of $X$, we have $y=\inf \left\{y_{n}\right\}$, i.e., $y_{n} \geqslant y$, for all $n \in \mathbb{N}$. 
As from similar argument above, we have $y_{n}>y$, for all $n \in \mathbb{N}$. Also, from the strict monotone decreasing of $f$ on the second variable, we get

$$
f\left(x, y_{n}\right)<f(x, y) .
$$

Therefore, from equations (11) and (12), we obtain

$$
f\left(x_{n}, y_{n}\right)<f(x, y) \Rightarrow x_{n+1}<f(x, y) \text {, for all } n \in \mathbb{N} .
$$

Since $x_{n}<x_{n+1}<f(x, y)$, for all $n \in \mathbb{N}$ and $x=\sup \left\{x_{n}\right\}$, then we obtain $x \leqslant f(x, y)$. Now, let $z_{0}=x$ and $z_{n+1}=f\left(z_{n}, y_{n}\right)$ then, by similar argument above the sequence $\left\{z_{n}\right\}$ is a nondecreasing Cauchy sequence, since $z_{0} \leqslant f\left(z_{0}, y_{0}\right)$ and converges to a point $z$ in $X$, implies that $z=\sup \left\{z_{n}\right\}$.

Since for all $n \in \mathbb{N}, x_{n} \leqslant x=z_{0} \leqslant f\left(z_{0}, y_{0}\right) \leqslant z_{n} \leqslant z$ then from (1), we have

$$
\begin{aligned}
d\left(x_{n+1}, z_{n+1}\right)= & d\left(f\left(x_{n}, y_{n}\right), f\left(z_{n}, y_{n}\right)\right) \\
\leqslant & \alpha \frac{d\left(x_{n}, f\left(x_{n}, y_{n}\right)\right)\left[1+d\left(z_{n}, f\left(z_{n}, y_{n}\right)\right)\right]}{1+d\left(x_{n}, z_{n}\right)} \\
& +\beta \frac{d\left(x_{n}, f\left(x_{n}, y_{n}\right)\right) d\left(z_{n}, f\left(z_{n}, y_{n}\right)\right)}{d\left(x_{n}, z_{n}\right)} \\
& +\gamma\left[d\left(x_{n}, f\left(x_{n}, y_{n}\right)\right)+d\left(z_{n}, f\left(z_{n}, y_{n}\right)\right)\right] \\
& +\delta\left[d\left(x_{n}, f\left(z_{n}, y_{n}\right)\right)+d\left(z_{n}, f\left(x_{n}, y_{n}\right)\right)\right]+\lambda d\left(x_{n}, z_{n}\right) .
\end{aligned}
$$

On taking limit as $n \rightarrow \infty$ in the above inequality, we get

$$
d(x, z) \leqslant(2 \delta+\lambda) d(x, z),
$$

but $2 \delta+\lambda<1$, then we obtain that $d(x, z)=0$. Hence $x=z=\sup \left\{x_{n}\right\}$, implies that $x \leqslant f(x, y) \leqslant x$. Thus, $x=f(x, y)$. Again following the similar above argument, we obtain that $y=f(y, x)$. Hence, $f$ has a coupled fixed point in $X \times X$.

For the existence and uniqueness of a coupled fixed point of $f$ over a complete partial ordered metric space $X$, we furnish the following partial order relation.

$$
(\mu, v) \leqslant(x, y) \Leftrightarrow x \geqslant \mu, y \leqslant v, \text { for any }(x, y),(\mu, v) \in X \times X .
$$

Theorem 2. Along the hypothesis stated in Theorem 1 and suppose that for every $(x, y),(r, s) \in$ $X \times X$, there exists $(u, v) \in X \times X$ such that $(f(u, v), f(v, u))$ is comparable to $(f(x, y), f(y, x))$ and $(f(r, s), f(s, r))$, then $f$ has a unique coupled fixed point in $X \times X$.

Proof. As we know from Theorem 1, the set of coupled fixed points of $f$ is non empty. Suppose that $(x, y)$ and $(r, s)$ are two coupled fixed points of the mapping $f$, then $x=f(x, y), y=f(y, x)$, $r=f(r, s)$ and $s=f(s, r)$. Now, we have to show that $x=r, y=s$ for the uniqueness of a coupled fixed point of $f$.

From hypotheses, there exists $(u, v) \in X \times X$ such that $(f(u, v), f(v, u))$ is comparable to $(f(x, y), f(y, x))$ and $(f(r, s), f(s, r))$. Put $u=u_{0}, v=v_{0}$ then choose $u_{1}, v_{1} \in X$ such that $u_{1}=f\left(u_{0}, v_{0}\right)$ and $v_{1}=f\left(v_{0}, u_{0}\right)$. Thus, following the proof of Theorem 1 , we construct two sequences $\left\{u_{n}\right\},\left\{v_{n}\right\}$ from $u_{n+1}=f\left(u_{n}, v_{n}\right)$ and $v_{n+1}=f\left(v_{n}, u_{n}\right)$ for all $n \in \mathbb{N}$. Similarly, define the sequences $\left\{x_{n}\right\},\left\{y_{n}\right\},\left\{r_{n}\right\}$ and $\left\{s_{n}\right\}$ by setting $x=x_{0}, y=y_{0}, r=r_{0}$ and $s=s_{0}$. As form Theorem 1, we have $x_{n} \rightarrow x=f(x, y), y_{n} \rightarrow y=f(y, x), r_{n} \rightarrow r=f(r, s)$ and $s_{n} \rightarrow s=f(s, r)$ for all $n \geqslant 1$. But $(f(x, y), f(y, x))=(x, y)$ and $\left(f\left(u_{0}, v_{0}\right), f\left(v_{0}, u_{0}\right)\right)=\left(u_{1}, v_{1}\right)$ are comparable and then we have $x \geqslant u_{1}$ and $y_{\leqslant} v_{1}$. Next to show that $(x, y)$ and $\left(u_{n}, v_{n}\right)$ are comparable, i.e., 
to show that $x \geqslant u_{n}$ and $y_{\leqslant} v_{n}$ for all $n \in \mathbb{N}$. Suppose the inequalities hold for some $n \geqslant 0$, then from strict mixed monotone property of $f$, we have $u_{n+1}=f\left(u_{n}, v_{n}\right) \leqslant f(x, y)=x$ and $v_{n+1}=f\left(v_{n}, u_{n}\right) \geqslant f(y, x)=y$. Therefore, we have $x \geqslant u_{n}$ and $y_{\leqslant} v_{n}$ for all $n \in \mathbb{N}$.

Again from (1), we have

$$
\begin{aligned}
d\left(x, u_{n+1}\right) & =d\left(f(x, y), f\left(u_{n}, v_{n}\right)\right) \\
& \leqslant \alpha \frac{d(x, f(x, y))\left[1+d\left(u_{n}, f\left(u_{n}, v_{n}\right)\right)\right]}{1+d\left(x, u_{n}\right)}+\beta \frac{d(x, f(x, y)) d\left(u_{n}, f\left(u_{n}, v_{n}\right)\right)}{d\left(x, u_{n}\right)} \\
& +\gamma\left[d(x, f(x, y))+d\left(u_{n}, f\left(u_{n}, v_{n}\right)\right)\right]+\delta\left[d\left(x, f\left(u_{n}, v_{n}\right)\right)+d\left(u_{n}, f(x, y)\right)\right]+\lambda d\left(x, u_{n}\right)
\end{aligned}
$$

which implies that

$$
d\left(x, u_{n+1}\right) \leqslant\left(\frac{\gamma+\delta+\lambda}{1-\gamma-\delta}\right) d\left(x, u_{n}\right)
$$

Similarly, we can obtain

$$
d\left(y, v_{n+1}\right) \leqslant\left(\frac{\gamma+\delta+\lambda}{1-\gamma-\delta}\right) d\left(y, v_{n}\right)
$$

Suppose $D=\frac{\gamma+\delta+\lambda}{1-\gamma-\delta}<1$, then from above equations, we have

$$
\begin{aligned}
d\left(x, u_{n+1}\right)+d\left(y, v_{n+1}\right) \leqslant & D\left[d\left(x, u_{n}\right)+d\left(y, v_{n}\right)\right] \\
\leqslant & D^{2}\left[d\left(x, u_{n-1}\right)+d\left(y, v_{n-1}\right)\right] \\
& \ldots \ldots \ldots \ldots \ldots \ldots \ldots \\
\leqslant & D^{n}\left[d\left(x, u_{0}\right)+d\left(y, v_{0}\right)\right] .
\end{aligned}
$$

Taking limit as $n \rightarrow+\infty$ to the above inequality, we get $\lim _{n \rightarrow+\infty} d\left(x, u_{n+1}\right)+d\left(y, v_{n+1}\right)=0$. Consequently, we obtain $\lim _{n \rightarrow+\infty} d\left(x, u_{n+1}\right)=0$ and $\lim _{n \rightarrow+\infty} d\left(y, v_{n+1}\right)=0$. Similarly, one can prove that $\lim _{n \rightarrow \infty} d\left(r, u_{n}\right)=0$ and $\lim _{n \rightarrow \infty} d\left(s, v_{n}\right)=0$.

Further form triangular inequality, we obtain that

$$
d(x, r) \leqslant d\left(x, u_{n}\right)+d\left(u_{n}, r\right) \text { and } d(y, s) \leqslant d\left(y, v_{n}\right)+d\left(v_{n}, s\right) .
$$

On taking limit as $n \rightarrow \infty$ to the above inequalities, we obtain that $d(x, r)=0=d(y, s)$, implies that $x=r$ and $y=s$. Hence, $f$ has a unique coupled fixed point in $X \times X$. This completes the proof.

Theorem 3. Along the hypotheses stated in Theorem 1 and if $x_{0}, y_{0}$ are comparable then $f$ has a coupled fixed point in $X \times X$.

Proof. Suppose $(x, y)$ is a coupled fixed point of $f$, then from Theorem 1, there exists two sequences $\left\{x_{n}\right\}$ and $\left\{y_{n}\right\}$ such that $x_{n} \rightarrow x$ and $y_{n} \rightarrow y$ in $X$.

Assume that $x_{0} \leqslant y_{0}$, then we have to show that $x_{n} \leqslant y_{n}$, for all $n \geqslant 0$. Suppose it hods for some $n \geqslant 0$. So, by the strict mixed monotone property of $f$, we get $x_{n+1}=f\left(x_{n}, y_{n}\right) \leqslant$ $f\left(y_{n}, x_{n}\right)=y_{n+1}$. Then, from the contraction condition (1), we get

$$
\begin{aligned}
d\left(x_{n+1}, y_{n+1}\right)= & d\left(f\left(x_{n}, y_{n}\right), f\left(y_{n}, x_{n}\right)\right) \\
\leqslant & \alpha \frac{d\left(x_{n}, f\left(x_{n}, y_{n}\right)\right)\left[1+d\left(y_{n}, f\left(y_{n}, x_{n}\right)\right)\right]}{1+d\left(x_{n}, y_{n}\right)} \\
& +\beta \frac{d\left(x_{n}, f\left(x_{n}, y_{n}\right)\right) d\left(y_{n}, f\left(y_{n}, x_{n}\right)\right)}{d\left(x_{n}, y_{n}\right)} \\
& +\gamma\left[d\left(x_{n}, f\left(x_{n}, y_{n}\right)\right)+d\left(y_{n}, f\left(y_{n}, x_{n}\right)\right)\right] \\
& +\delta\left[d\left(x_{n}, f\left(y_{n}, x_{n}\right)\right)+d\left(y_{n}, f\left(x_{n}, y_{n}\right)\right)\right]+\lambda d\left(x_{n}, y_{n}\right) .
\end{aligned}
$$


On taking limit as $n \rightarrow \infty$, we get

$$
d(x, y) \leqslant(2 \delta+\lambda) d(x, y)
$$

which is a contradiction, since $2 \delta+\lambda<1$. Thus, $d(x, y)=0$. Therefore, we have $f(x, y)=$ $=x=y=f(y, x)$. Similarly, we can also show that $f(x, y)=x=y=f(y, x)$ by considering $y_{0} \leqslant x_{0}$. Hence, $(x, y)$ is a coupled fixed point of $f$ in $X \times X$.

\section{Remarks:}

1. If $\alpha=\gamma=\delta=0$, in above Theorems, we obtain Theorems 2.1 and Theorem 2.2 of Ciric et al. [30].

2. If $\alpha=0$ in above Theorems, we can get Theorem 2.1-Theorem 2.3 of Chandok et al. [38].

3. Banach [1] type contraction in partially ordered metric spaces can get by taking $\alpha=\beta=$ $=\gamma=\delta=0$.

4. Kannan [7] type contraction for coupled fixed point theorem in partially ordered metric spaces can get by putting $\alpha=\beta=\delta=\lambda=0$ in above Theorem 2.1-Theorem 2.3.

5. Chatterjee [3] type contraction for coupled fixed point theorem in partially ordered metric spaces can obtain by giving $\alpha=\beta=\gamma=\lambda=0$ in above Theorem 2.1-Theorem 2.3.

6. Singh and Chatterjee [9] type contraction for coupled fixed point theorem in partially ordered metric spaces can get by giving $\alpha=\gamma=0$ in above Theorem 2.1-Theorem 2.3.

\section{Applications}

In this section, we state some applications of the main result to a self mapping involving an integral type contractions.

Let us consider the set of all functions $\chi$ defined on $[0, \infty)$ satisfying the following conditions:

1. Each $\chi$ is Lebesgue integrable mapping on each compact subset of $[0, \infty)$.

2. For any $\epsilon>0$, we have $\int_{0}^{\epsilon} \chi(t) d t>0$.

Theorem 4. Let $(X, d, \leqslant)$ be a complete partially ordered metric space. Suppose that a self mapping $f: X \times X \rightarrow X$ has a strict mixed monotone property on $X$ satisfying the following condition

$$
\begin{aligned}
\int_{0}^{(d(f(x, y), f(\mu, v))} \varphi(t) d t & \leqslant \alpha \int_{0}^{\frac{d(x, f(x, y))[1+d(\mu, f(\mu, v)]}{1+d(x, \mu)}} \varphi(t) d t+\beta \int_{0}^{\frac{d(x, f(x, y)) d(\mu, f(\mu, v))}{d(x, \mu)}} \varphi(t) d t \\
& +\gamma \int_{0}^{d(x, f(x, y))+d(\mu, f(\mu, v))} \varphi(t) d t+\delta \int_{0}^{d(x, f(\mu, v))+d(\mu, f(x, y))} \varphi(t) d t \\
& +\lambda \int_{0}^{d(x, \mu)} \varphi(t) d t
\end{aligned}
$$

for all $x, y, \mu, v \in X$ with $x \geqslant \mu$ and $y \leqslant v, \varphi(t)$ is a function satisfies the above conditions defined on $[0, \infty)$ and $\alpha, \beta, \gamma, \delta, \lambda \in[0,1)$ with $0 \leqslant \alpha+\beta+2(\gamma+\delta)+\lambda<1$. Suppose that either $f$ is continuous or $X$ has an ordered complete property $(O C)$ then $f$ has a coupled fixed point $(x, y) \in X \times X$, if there exists two points $x_{0}, y_{0} \in X$ with $x_{0}<f\left(x_{0}, y_{0}\right)$ and $y_{0}>f\left(y_{0}, x_{0}\right)$. 
Similarly, we can obtain the following coupled fixed point results in partially ordered metric space, by taking $\gamma=\delta=0, \beta=0, \beta=\gamma=0$ and $\beta=\delta=0$ in Theorem 4 .

Theorem 5. Let $(X, d, \leqslant)$ be a complete partially ordered metric space. Suppose that a self mapping $f: X \times X \rightarrow X$ has a strict mixed monotone property on $X$ satisfying the following condition

$$
\begin{aligned}
\int_{0}^{(d(f(x, y), f(\mu, v))} \varphi(t) d t & \leqslant \alpha \int_{0}^{\frac{d(x, f(x, y))[1+d(\mu, f(\mu, v))]}{1+d(x, \mu)}} \varphi(t) d t+\beta \int_{0}^{\frac{d(x, f(x, y)) d(\mu, f(\mu, v))}{d(x, \mu)}} \varphi(t) d t \\
& +\lambda \int_{0}^{d(x, \mu)} \varphi(t) d t
\end{aligned}
$$

for all $x, y, \mu, v \in X$ with $x \geqslant \mu$ and $y \leqslant v, \varphi(t)$ is a function satisfies the above conditions defined on $[0, \infty)$ and $\alpha, \beta, \lambda \in[0,1)$ with $0 \leqslant \alpha+\beta+\lambda<1$. Suppose that either $f$ is continuous or $X$ has an ordered complete property (OC) then $f$ has a coupled fixed point $(x, y) \in X \times X$, if there exists two points $x_{0}, y_{0} \in X$ with $x_{0}<f\left(x_{0}, y_{0}\right)$ and $y_{0}>f\left(y_{0}, x_{0}\right)$.

Theorem 6. Let $(X, d, \leqslant)$ be a complete partially ordered metric space. Suppose that a self mapping $f: X \times X \rightarrow X$ has a strict mixed monotone property on $X$ satisfying the following condition

$$
\begin{aligned}
\int_{0}^{(d(f(x, y), f(\mu, v))} \varphi(t) d t & \leqslant \alpha \int_{0}^{\frac{d(x, f(x, y))[1+d(\mu, f(\mu, v))]}{1+d(x, \mu)}} \varphi(t) d t+\gamma \int_{0}^{d(x, f(x, y))+d(\mu, f(\mu, v))} \varphi(t) d t \\
& +\delta \int_{0}^{d(x, f(\mu, v))+d(\mu, f(x, y))} \varphi(t) d t+\lambda \int_{0}^{d(x, \mu)} \varphi(t) d t
\end{aligned}
$$

for all $x, y, \mu, v \in X$ with $x \geqslant \mu$ and $y \leqslant v, \varphi(t)$ is a function satisfies the above conditions defined on $[0, \infty)$ and $\alpha, \gamma, \delta, \lambda \in[0,1)$ with $0 \leqslant \alpha+2(\gamma+\delta)+\lambda<1$. Suppose that either $f$ is continuous or $X$ has an ordered complete property (OC) then $f$ has a coupled fixed point $(x, y) \in X \times X$, if there exists two points $x_{0}, y_{0} \in X$ with $x_{0}<f\left(x_{0}, y_{0}\right)$ and $y_{0}>f\left(y_{0}, x_{0}\right)$.

Theorem 7. Let $(X, d, \leqslant)$ be a complete partially ordered metric space. Suppose that a self mapping $f: X \times X \rightarrow X$ has a strict mixed monotone property on $X$ satisfying the following condition

$$
\begin{aligned}
\int_{0}^{(d(f(x, y), f(\mu, v))} \varphi(t) d t & \leqslant \alpha \int_{0}^{\frac{d(x, f(x, y))[1+d(\mu, f(\mu, v))]}{1+d(x, \mu)}} \varphi(t) d t+\delta \int_{0}^{d(x, f(\mu, v))+d(\mu, f(x, y))} \varphi(t) d t \\
& +\lambda \int_{0}^{d(x, \mu)} \varphi(t) d t
\end{aligned}
$$

for all $x, y, \mu, v \in X$ with $x \geqslant \mu$ and $y \leqslant v, \varphi(t)$ is a function satisfies the above conditions defined on $[0, \infty)$ and $\alpha, \delta, \lambda \in[0,1)$ with $0 \leqslant \alpha+2 \delta+\lambda<1$. Suppose that either $f$ is continuous or $X$ has an ordered complete property (OC) then $f$ has a coupled fixed point $(x, y) \in X \times X$, if there exists two points $x_{0}, y_{0} \in X$ with $x_{0}<f\left(x_{0}, y_{0}\right)$ and $y_{0}>f\left(y_{0}, x_{0}\right)$.

Theorem 8. Let $(X, d, \leqslant)$ be a complete partially ordered metric space. Suppose that a self mapping $f: X \times X \rightarrow X$ has a strict mixed monotone property on $X$ satisfying the following condition

$$
\begin{aligned}
\int_{0}^{(d(f(x, y), f(\mu, v))} \varphi(t) d t & \leqslant \alpha \int_{0}^{\frac{d(x, f(x, y))[1+d(\mu, f(\mu, v))]}{1+d(x, \mu)}} \varphi(t) d t+\gamma \int_{0}^{d(x, f(x, y))+d(\mu, f(\mu, v))} \varphi(t) d t \\
& +\lambda \int_{0}^{d(x, \mu)} \varphi(t) d t
\end{aligned}
$$


for all $x, y, \mu, v \in X$ with $x \geqslant \mu$ and $y \leqslant v, \varphi(t)$ is a function satisfies the above conditions defined on $[0, \infty)$ and $\alpha, \gamma, \lambda \in[0,1)$ with $0 \leqslant \alpha+2 \gamma+\lambda<1$. Suppose that either $f$ is continuous or $X$ has an ordered complete property $(O C)$ then $f$ has a coupled fixed point $(x, y) \in X \times X$, if there exists two points $x_{0}, y_{0} \in X$ with $x_{0}<f\left(x_{0}, y_{0}\right)$ and $y_{0}>f\left(y_{0}, x_{0}\right)$.

\section{References}

[1] S.Banach, Sur les operations dans les ensembles abstraits et leur application aux equations untegrales, Fund. Math., 3(1922), 133-181.

[2] B.K.Dass, S.Gupta, An extension of Banach contraction principle through rational expression, Indian Journal of Pure and Applied Mathematics, 6(1975), 1455-1458.

[3] S.K.Chetterjee, Fixed point theorems, C.R. Acad. Bulgara Sci., 25(1972), 727-730.

[4] M.Edelstein, On fixed points and periodic points under contraction mappings, J. Lond. Math. Soc., 37(1962), 74-79.

[5] G.C.Hardy, T.Rogers, A generalization of fixed point theorem of S. Reich, Can. Math. Bull., 16(1973), 201-206.

[6] D.S.Jaggi, Some unique fixed point theorems, Indian J. Pure Appl. Math., 8(1977), 223-230.

[7] R.Kannan, Some results on fixed points-II, Am. Math. Mon., 76(1969), 71-76.

[8] S.Reich, Some remarks concerning contraction mappings, Can. Math. Bull, 14(1971), $121-124$.

[9] M.R.Singh, A.K.Chatterjee, Fixed point theorems, Commun. Fac. Sci. Univ. Ank. Series A1, 37(1988), 1-4.

[10] D.R.Smart, Fixed Point Theorems, Cambridge University Press, Cambridge, 1974.

[11] C.S.Wong, Common fixed points of two mappings, Pac. J. Math., 48,(1973) 299-312.

[12] R.P.Agarwal, M.A.El-Gebeily, D.O'Regan, Generalized contractions in partially ordered metric spaces, Appl. Anal., 87(2008), 1-8.

[13] I.Altun, B.Damjanovic, D.Djoric, Fixed point and common fixed point theorems on ordered cone metric spaces, Appl. Math. Lett., 23(2010), 310-316.

[14] A.Amini-Harandi, H.Emami, A fixed point theorem for contraction type maps in partially ordered metric spaces and application to ordinary differential equations, Nonlinear Analysis: Theory, Methods \& Applications, 72(2010), 2238-2242.

[15] M.Arshad, A.Azam, P.Vetro, Some common fixed results in cone metric spaces, Fixed Point Theory Appl., 2009(2009), Article ID 493965.

[16] M.Arshad, J.Ahmad, E.Karapinar, Some common fixed point results in rectangular metric spaces, Int. J. Anal., 2013(2013), Article ID 307234.

[17] T.G.Bhaskar, V.Lakshmikantham, Fixed point theory in partially ordered metric spaces and applications, Nonlinear Analysis: Theory, Methods \& Applications, 65(2006), 1379-1393.

[18] S.Hong, Fixed points of multivalued operators in ordered metric spaces with applications, Nonlinear Analysis: Theory, Methods \& Applications, 72(2010), 3929-3942. 
[19] J.J.Nieto, R.R.Lopez, Contractive mapping theorems in partially ordered sets and applications to ordinary differential equations, Order, 22(2005), 223-239.

[20] J.J.Nieto, R.R.Lopez, Existence and uniqueness of fixed point in partially ordered sets and applications to ordinary differential equation, Acta Math. Sin. Engl. Ser., 23(2007), no. 12, $2205-2212$.

[21] M.Ozturk, M.Basarir, On some common fixed point theorems with rational expressions on cone metric spaces over a Banach algebra, Hacet. J. Math. Stat., 41(2012), no. 2, 211-222 .

[22] A.C.M.Ran, M.C.B.Reurings, A fixed point theorem in partially ordered sets and some application to matrix equations, Proc. Am. Math. Soc., 132(2004), 1435-1443.

[23] E.S.Wolk, Continuous convergence in partially ordered sets, Gen. Topol. Appl., 5(1975), $221-234$.

[24] X.Zhang, Fixed point theorems of multivalued monotone mappings in ordered metric spaces, Appl. Math. Lett., 23(2010), 235-240.

[25] H.Aydi, E.Karapinar, W.Shatanawi, Coupled fixed point results for $(\psi, \varphi)$-weakly contractive condition in ordered partial metric spaces, Comput. Math. Appl., 62(2011), no. 12, 4449-4460.

[26] V.Berinde, Generalized coupled fixed point theorems for mixed monotone mappings in partially ordered metric spaces, Nonlinear Analysis: Theory, Methods and Applications, 74(2011), no. 18, 7347-7355.

[27] V.Berinde, Coupled fixed point theorems for $F$-contractive mixed monotone mappings in partially ordered metric spaces, Nonlinear Analysis: Theory, Methods and Applications, 75(2012), no. 6, 3218-3228.

[28] V.Berinde, M.Pacurar, Coupled and triple fixed point theorems for mixed monotone almost contractive mappings in partially ordered metric spaces, Journal of Nonlinear and Convex Analysis, 18(2017), no. 4, 651-659.

[29] B.S.Choudhury, A.Kundu, A coupled coincidence point result in partially ordered metric spaces for compatible mappings, Nonlinear Analysis: Theory, Methods \& Applications, 73(2010), 2524-2531.

[30] L.Ciric, M.O.Olatinwo, D.Gopal, G.Akinbo, Coupled point theorems for mappings satisfying a contractive condition of rational type on a partially ordered metric space, Adv. Fixed Point Theory, 2(2012), 1-8.

[31] E.Karapinar, Couple fixed point on cone metric spaces, Gazi Univ. J. Sci., 24(2011), no. 1, $51-58$.

[32] V.Lakshmikantham, L.B.Ciric, Couple fixed point theorems for nonlinear contractions in partially ordered metric spaces, Nonlinear Analysis: Theory, Methods \& Applications, 70(2009), 4341-4349.

[33] N.V.Luong, N.X.Thuan, Coupled fixed points in partially ordered metric spaces and application, Nonlinear Analysis: Theory, Methods \& Applications, 74(2011), 983-992.

[34] A. Petrusel, G.Petrusel, Discrete Dynamics in Nature and Society, 2015(2015), Article ID 143510. DOI: $10.1155 / 2015 / 143510$ 
[35] A.Petrusel, G.Petrusel, J.C.Yao, Contributions to the coupled coincidence point problem in b-metric spaces with applications, FILOMAT, 31(2017), no. 10, 3173-3180.

[36] A.Petrusel, G.Petrusel, J.C.Yao, Coupled fixed points theorems in quasi metric spaces without mixed monotonicity, Carpathian J. Math., 35(2019), no. 2, 169-176 .

[37] B.Samet, Coupled fixed point theorems for a generalized Meir-Keeler contraction in partially ordered metric spaces, Nonlinear Anal., 74(2010), no. 12, 4508-4517.

[38] S.Chandok, T.D.Narang, M.A.Taoudi, Some coupled fixed point theorems for mappings satisfying a generalized contractive condition of rational type, Palestine Journal of Mathematics, 4(2015), no. 2, 360-366.

[39] C.Vetro, H.K.Nashine, B.Samet, Monotone generalized nonlinear contractions and fixed point theorems in ordered metric spaces, Mathematical and Computer Modelling, 54(2011), $712-720$.

[40] C.Vetro, B.Samet, Coupled fixed point theorems for multi-valued nonlinear contraction mappings in partially ordered metric spaces, Nonlinear Analysis, 74(2011), 4260-4268.

[41] C.Vetro, Coupled coincidence points for compatible mappings satisfying mixed monotone property, The Journal of Nonlinear Sciences and its Applications 5(2012), 104-114.

[42] C.Vetro, Coupled common fixed point theorems in partially ordered G-metric spaces for nonlinear contractions, Mathematica Moravica, 18(2014), 45-62.

\title{
Обобщенные сжатия для связанных теорем о неподвижных точках в частично упорядоченных метрических пространствах
}

\author{
Н. Сешагири Рао \\ Научно-технический университет Адамы \\ Адама, Эфиопия \\ Карусала Каляни \\ Фонд науки, технологий и исследований Вигнан \\ Прадеш, Индия
}

\begin{abstract}
$\overline{\text { Аннотация. Цель этой статьи - установить некоторые связанные теоремы о неподвижной точ- }}$ ке для самопредставления, удовлетворяющего определенным рациональным сокращениям типов наряду со строго смешанной монотонной собственностью в метрическом пространстве, снабженном частичным порядком. Также мы дали результат существования и единственности связанной неподвижной точки для отображения. Этот результат обобщает и расширяет несколько хорошо известных в литературе результатов.
\end{abstract}

Ключевые слова: частично упорядоченные метрические пространства, рациональные сокращения, связанная фиксированная точка, монотонная собственность. 